\title{
RECURSOS MIDIÁTICOS E MULTILETRAMENTOS NO ENSINO DE LÍNGUA PORTUGUESA ${ }^{1}$
}

\author{
Thaíse Duarte Temoteo Gonçalves, UFCG, taise_cz@ hotmail.com \\ Hérica Paiva Pereira, UFCG, hericap2@gmail.com
}

\begin{abstract}
RESUMO
Com o avanço das tecnologias e das mídias digitais surgem novos gêneros textuais, que por sua vez, estimulam a escola a formar sujeitos multiletrados, ou seja, capazes de desenvolverem-se nesta área. Nesse contexto, o presente trabalho tem como objetivo compreender o processo de retextualização do gênero canção para o gênero hiperconto, por meio dos multiletramentos, como prática pedagógica motivadora e significativa para o aluno do século XXI. Quanto ao procedimento metodológico, adotamos uma pesquisa bibliográfica, de cunho qualitativo, que tem por finalidade compreender como ocorre o processo de retextualização através dos multiletramentos. Além disso, propomos uma atividade de retextualização, do gênero canção para o gênero hiperconto, sob uma perspectiva dos multiletramentos, a ser realizada numa turma de $2^{\circ}$ ano do Ensino Médio, com a intenção de contribuir para o trabalho docente em sala de aula. Os resultados dos estudos apontam que, a retextualização de gêneros textuais, através dos multiletramentos, é uma atividade que ocorre de forma atrativa e significativa para o aluno por envolvê-lo em suas práticas sociais.
\end{abstract}

PALAVRAS-CHAVE: Multiletramentos; Gêneros textuais; Retextualização.

\section{MEDIA RESOURCES AND MULTILETTERING IN PORTUGUESE LANGUAGE TEACHING}

\begin{abstract}
As the digital technologies and digital media evolves, new textual genres are emerging, which stimulate the school to form multilevel individuals, that is, capable of developing in this area. In this context, this work aims to understand the process of retextualization of the genre song to the "hypertale" [hiperconto] genre, through "multilettering" [multiletramentos], as a motivational and meaningful pedagogical practice for the student of the 21 st century. As for the methodological procedure, we adopted a qualitative bibliographical research whose purpose is to understand how the process of retextualization through multilettering occurs. In addition, we propose a retextualization activity, from the song genre to the hypertale genre, in a multilevel perspective, to be carried out in a 2nd year High School class, with the intention of contributing to the teaching work in the classroom. The results of the studies indicate that

\footnotetext{
${ }^{1} \mathrm{O}$ presente trabalho (não) contou com apoio financeiro de nenhuma natureza para sua realização.
} 
the retextualization of textual genres through multilettering is an activity that occurs in an attractive and meaningful way for the student by involving him in his social practices.

KEYWORDS: Multiletterig; Textual genres; Retextualizatio;

\section{RECURSOS MEDIATICOS Y MULTIALFABETIZACION EN LA ENSEÑANZA DE LA LENGUA PORTUGUESA}

\section{RESUMEN}

Con el avance de las tecnologías y las mídias digitales, surgen nuevos géneros textuales, que estimulan a la escuela a formar sujetos multialfabetizados, o sea, capaces de desarrollarse en esta área. En ese contexto, el presente trabajo tiene como objetivo comprender el proceso de retextualización del género canción para el género hipercuento, por medio de la multialfabetizacion, como práctica pedagógica motivadora y significativa para el alumno del siglo XXI. El procedimiento metodológico se trata de una investigación bibliográfica, cualitativa, que tiene por finalidad comprender cómo ocurre el proceso de retextualización por medio de la multialfabetizacion. En ese sentido, proponemos una actividad de retextualización, del género canción para el género hipercuento, bajo una perspectiva de la multialfabetizacion, a ser realizada en un aula del $2^{\circ}$ año de la Escuela Secundaria, con la intención de contribuir con el trabajo del profesor. Los resultados de los estudios apuntan que, la retextualización de géneros textuales, por medio de la multialfabetizacion, es una actividad atractiva y significativa para el alumno por lograr involucrarlo en sus prácticas sociales.

PALABRAS CLAVES: Multilalfabetizacion; Géneros textuales; Retextualización;

\section{INTRODUÇÃO}

O multiletramento não é apenas a junção de vários tipos de letramentos, mas uma diversidade de linguagens e modos de comunicação, por isso, o trabalho com multiletramentos pode ou não envolver o uso de tecnologias, mas em sua grande maioria irá envolver, nas práticas reflexivas em sala de aula, uma multiplicidade de linguagens, de culturas, de modos e meios nos quais o texto possa se materializar de forma mais atraente e possibilitar uma interação e cooperação de seus interlocutores.

Com isso, questiona-se como o professor poderá realizar suas aulas de língua portuguesa de modo a formar estudantes multiletrados no uso e produção dos gêneros textuais. É aqui que pensamos na retextualização como ponte para esse processo de ensino aprendizagem dos gêneros no multiletramento. 
Nesta perspectiva, este trabalho objetiva compreender o processo de retextualização do gênero canção para o gênero hiperconto, por meio dos multiletramentos, como prática pedagógica motivadora e significativa para alunos do século XXI.

Para fundamentar este trabalho nos baseamos principalmente em Rojo (2012), Marcuschi (2008; 2010), Spalding (2010), Tatit (2003), Dias (2012), entre outros. Esses estudiosos contribuíram para o desenvolvimento do trabalho no que se refere a conhecimentos teóricos linguísticos acerca dos multiletramentos, bem como do processo de retextualização e definição dos gêneros textuais canção e hiperconto. E como metodologia, esta pesquisa é bibliográfica por tratar de estudos realizados por meio de livros, textos orais, escritos e digitais acadêmicos; e de cunho qualitativo porque busca compreender como ocorre o processo de retextualização através dos multiletramentos.

A intenção da pesquisa é contribuir com a prática dos professores de língua portuguesa, para isso, elaboramos uma proposta de intervenção em uma turma de $2^{\circ}$ ano do Ensino Médio, na qual os estudantes terão contato com gêneros orais e escritos, e produzirão um texto a partir do processo de retextualização, tendo como gênero base: a canção, que é um gênero oral e de tradição popular, para o gênero escrito e digital: o hiperconto. Queremos com isso, mostrar um modo de formar estudantes multiletrados que conhecem e são capazes de produzir os diversos gêneros textuais que circulam na sociedade, sendo estes digitais ou não.

\section{A CONSTRUÇÃO DE NOVOS GÊNEROS TEXTUAIS E OS MULTILETRAMENTOS}

Ao considerar que a sociedade do século XXI é uma sociedade digital, é necessário um ensino atrelado aos multiletramentos, ou seja, ao uso de novas tecnologias e mídias digitais.

De acordo com Rojo (2012) há dois pontos importantes no que se refere aos multiletramentos: a questão cultural e a questão da constituição dos textos. A questão da multiplicidade cultural nos leva a pensar na nossa cultura, hoje uma cultura hibrida, tanto fruto de um país miscigenado como também de uma era digital.

Ainda para a autora, atualmente, é difícil classificar um tipo de cultura "pura", seja ela erudita/popular ou central/marginal, a verdade é que com o passar dos anos desenvolveu-se 
um hibridismo cultural no qual existe uma mistura de culturas indissociáveis, a esta mistura de culturas nós chamamos multiplicidade de culturas.

Também é importante destacarmos que com o avanço tecnológico houve um progresso nos letramentos e nas estéticas de gêneros, sendo assim, é necessário um estudo aprofundado dessas novas estéticas e critérios para análises, sejam estas puramente estéticas ou mesmo semânticas, dependendo do público que está analisando.

Os multiletramentos também referem-se à múltiplas linguagens que envolvem diferentes recursos, como um texto com imagens, arranjos musicais, escrita, etc, tornando-o multimodal. Com os avanços tecnológicos e a acessibilidade cada vez mais facilitada às tecnologias esse tipo de texto está cada dia mais comum não só entre os jovens, mas entre todos os falantes em geral.

A respeito desses textos que envolvem diversos recursos midiáticos sejam estes digitais, audiovisuais ou não, Rojo nos fala:

É o que tem sido chamado de multimodalidade ou multissemiose dos textos contemporâneos, que exigem multiletramentos. Ou seja, textos compostos de muitas linguagens (ou modos, ou semioses) e que exigem capacidades e práticas de compreensão e produção de cada uma delas (multiletramentos) para fazer significar. (ROJO, 2012, p. 19).

Podemos concluir então que os usuários da língua precisam ser, além de letrados, multiletrados, para assim, dominar as muitas linguagens encontradas nos mais variados gêneros textuais, tornando a prática de compreensão mais efetiva. Sendo assim, sentimos a necessidade de novas práticas tanto de produção, para isso conhecer e saber utilizar novos recursos, como fazer edições, animações, curtas, apresentações audiovisuais.

Para Rojo (2012) ao caracterizarmos os multiletramentos podemos perceber que eles permitem interação e colaboração entre os leitores e autores, eles também modificam e vão além das relações de propriedade, já antes estabelecidas, são como já antes dito híbridos, uma mistura tanto de linguagens, como de modos, mídias e culturais, por isso o prefixo "multi”, os multiletramentos são essa diversidade de modos, culturais e linguagens.

Uma ferramenta que se encaixa perfeitamente nos multiletramentos são os hipertextos, textos que já não cabem em si uma só linguagem, textos que são interativos e que vão além do 
ler e compreender, permitindo uma interação real, diferenciando-se das mídias anteriores, esta permite interações via internet que acontecem em tempo real e sem um limite de distâncias.

Concluímos que é uma necessidade atual formar pessoas multiletradas, uma vez que as situações de comunicação do século XXI exigem pessoas que dominem os multiletramentos para só assim acontecer de fato uma boa compreensão. Assim, só formaremos usuários competentes em sua própria língua, quando as escolas passarem a ensinar usando práticas de multiletramentos.

\subsection{GÊNEROS TEXTUAIS: UMA FERRAMENTA PEDAGÓGICA}

De acordo com Marcuschi (2010, p.19) “[...] os gêneros são fenômenos históricos, profundamente vinculados à vida cultural e social. Fruto do trabalho coletivo, os gêneros contribuem para ordenar e estabilizar as atividades comunicativas no dia a dia." O autor ainda fala que os gêneros, além de contribuir para uma organização e padronização dos eventos comunicativos, eles não são rígidos nem estanques, pelo contrário, esses se caracterizam por poderem adaptar-se às variadas atividades comunicativas em que são utilizados. Portanto, os gêneros são atividades socioculturais e que atualmente existe uma infinidade deles que circulam pela sociedade, exercendo assim um importante papel comunicativo, principalmente na sociedade digital, na qual surgem gêneros novos a todo o momento.

No que diz respeito ao uso dos gêneros textuais no ensino de língua através dos multiletramentos, podemos constatar que é uma necessidade do nosso século, porque o uso de novas tecnologias e mídias digitais é a comunicação utilizada pela sociedade em geral.

De acordo com Rojo (2012) as novas tecnologias não devem ser vistas como vilãs nas escolas, mas como aliados. Com isso, entendemos que ao invés de proibir o uso de recursos digitais e de internet na escola, o professor deve planejar suas aulas para se aliar com estes novos recursos, assim, propondo atividades nas quais os estudantes possam usar o celular, a internet, podendo fazer pesquisas, filmagens, fotos, uma infinidade de exercícios sem deixar os recursos tecnológicos, que são tão atraentes de lado, como promovendo atividades através de Skype, chat, vídeo produções e vídeo aulas. A autora afirma ainda que, para acontecer práticas pedagógicas que envolvam os multiletramentos é necessária, uma ética que seja cultural, plural e democrática, assim como várias estéticas, que se aplicam às diversas práticas 
letradas. Portanto, é preciso que a escola se atente aos letramentos críticos para "transformar o ‘consumidor acrítico' - se é que ele de fato existe- em 'analista crítico'”. (ROJO, 2012, p. 28).

A estudiosa afirma que é de suma importância formar um usuário da língua que seja competente de forma técnica nas ferramentas, sejam estas, o uso dos textos como também a produção. Essa competência técnica só é adquirida através das práticas de multiletramentos. Pois, são essas práticas que colocam os estudantes em contato com as diversas técnicas e linguagens usadas pela sociedade. Assim, o trabalho da escola deve estar preocupado em propiciar atividades práticas, com o objetivo de desenvolver no aluno a criticidade e a capacidade de construir sentidos. Para isto, é imprescindível que este aluno seja capaz de transformar discursos e significações, sejam estas no ato na recepção ou na produção dos gêneros textuais. Logo, o ensino deve acontecer a partir do enquadramento dos letramentos críticos, pois estes interpretam os contextos sociais e culturais de circulação e produção dos hipertextos, buscando uma produção transformada deste, ou seja, uma retextualização.

Concluímos que, essa proposta didática, voltada para o ensino por meio dos gêneros textuais com o uso dos multiletramentos "[...] condiz com os princípios da pluralidade cultural e da diversidade de linguagens envolvidos no conceito de multiletramentos." (ROJO, 2012, p. 30). Felizmente, grande parte dos professores brasileiros demonstra grande interesse em adequar suas práticas pedagógicas aos letramentos e multiletramentos, para isso se torna necessária uma formação mais aprofundada quanto ao tema e uma reorganização das práticas pedagógicas visando uma melhor aprendizagem.

\subsection{O PROCESSO DE RETEXTUALIZAÇÃO NA PERSPECTIVA DE MARCUSCHI}

O processo de retextualização passou, recentemente, a ser objeto de pesquisa de alguns estudiosos da língua, entre estes merece maior destaque Marcuschi (2010) que se dedicou a compreender e explicá-lo.

De acordo com o estudioso, a retextualização acontece naturalmente dentro dos processos de textualização, uma vez que, esta abrange operações complexas que intervêm no código e no significado, trazendo a tona diversos aspectos, algumas vezes não compreendidos da relação existente entre oralidade e escrita. 
O estudioso expõe quatro possibilidades de retextualização: da fala para a fala, da fala para a escrita, da escrita para a fala e da escrita para a escrita. Assim, é possível compreendermos e refletirmos que retextualizamos cotidianamente sem saber que o estamos fazendo, pois a retextualização é uma prática social natural aos falantes de uma língua.

Percebemos que ao realizar a retextualização da fala para a escrita o usuário da língua tem consciência do que está fazendo e que este processo deve seguir padrões, mesmo que existam diversas formas de retextualizar o falante deve seguir a estrutura composicional do gênero para o qual este está transformando o texto.

Concluímos que o processo de retextualização é um caminho enriquecedor para que o aluno possa transitar, por diferentes gêneros textuais orais e escritos, que circulam na sociedade em geral, envolvendo, da fala para a fala, da fala para a escrita, da escrita para a fala e da escrita para a escrita.

\subsection{GÊNERO CANÇÃO}

Segundo Costa (2010, p. 118) “[...] a canção é um gênero híbrido, de caráter intersemiótico, pois é resultado da conjugação de dois tipos de linguagens, a verbal e a musical (ritmo e melodia)". Com isso, percebemos que a canção tem a capacidade de articular as duas linguagens simultaneamente e que ambas são indissociáveis. O autor afirma que a canção ocorre em veículo vocal e que esta veiculação deve estar atenta e dentro dos padrões de entonação e ritmo estabelecidos para a linguagem musical. Diante disso, é importante destacar que os padrões de entonação e ritmo são extremamente flexíveis, visto que cada subgênero da canção, como rap, forró, pop, sertanejo, etc., exigirá um ritmo e uma entonação diferente de acordo com seus padrões próprios.

Nesse sentido, canção é uma fala disfarçada, e esse disfarce consiste em transformar a entonação, que lhe é natural, por uma frequência de entonação harmônica regular. Com isso, essa regulação atribui uma padronização da fala, estabelecendo um determinado modo de vocalizar cada texto, de acordo com seus acentos rítmicos e sua regulação de pulsação. Ainda segundo o autor, a fala não é subsumida de um todo no canto, pelo contrário a canção popular tem como característica manter o elo com a fala coloquial. Ele então confirma ao dizer que "a 
eficácia do gênero textual canção está na síntese entre a voz que fala e a voz que canta”. (COSTA, 2012, p. 120).

Segundo Costa (2010) o recente interesse pedagógico pelo gênero textual canção demonstra que cada vez mais os gêneros orais estão tendo espaço nas escolas, assim como também a produção lítero-musical ajuda na construção da identidade do país. Com isso, reconhecemos a importância de o professor ao abordar o gênero textual canção, ter domínio da estrutura composicional que contempla: os aspectos melódicos, o ritmo, os interlocutores e a produção oral, destacando que a forma escrita na canção só deve ocorrer posterior à sua produção já que essa pertence a outro gênero conhecido como letra de música.

O professor, a partir desses conhecimentos, deve traçar objetivos claros quanto ao ensino aprendizagem do gênero canção, com o cuidado para que as aulas não sejam consideradas um mero espaço de lazer. Ainda nesse processo, cabe ao professor formar estudantes que sejam ouvintes críticos de canções, sabendo considerar todos os aspectos que envolvem o gênero, condições de produção, interlocutores, finalidade, entre outros.

Vale ressaltar que, por a canção ser um gênero oral, ele ainda tem pouco espaço nas aulas de língua, dado que para muitos gestores, cantar em sala de aula é perder tempo de conteúdo. Não obstante essas dificuldades, essa nova geração de professores dá cada vez mais abertura a novos gêneros, para serem usados em fins pedagógicos, e um destes é a canção.

Concluímos que o trabalho com a canção deve ocorrer de forma planejada e estruturada, considerando sua estrutura composicional e suas condições de produção, tendo o professor estabelecido propósitos para suas aulas.

\subsection{GÊNERO HIPERCONTO}

O hiperconto é um gênero recente e digital que, assim como outros gêneros digitais, está em evidência no século XXI e fazem parte do cotidiano de todos. Para a leitura e produção desses novos gêneros híbridos e digitais é necessário que os leitores sejam multiletrados e tenha habilidades com o uso das tecnologias, por isso, o hiperconto se assemelha ao conto tradicional, por ser uma narrativa curta, e se distancia pelo fato de possuir diversos recursos tecnológicos. Vejamos como Spalding (2010) conceitua o hiperconto:

O hiperconto seria uma versão do conto para a Era Digital. Sendo ainda um conto, de tradição milenar, requer narratividade, intensidade, tensão, 
ocultamento, autoria. O texto, naturalmente, ainda deve ser o cerne do hiperconto, preservando seu caráter literário. Mas um bom hiperconto será capaz de aproveitar as ferramentas das novas tecnologias para potencializar a história que conta da mesma forma que os livros infanto-juvenis, por exemplo, têm se utilizado da ilustração. Imagens, em movimento ou não, áudios, hiperlinks, interatividade e quebra da linearidade são apenas algumas das possibilidades do hiperconto. Claro que um bom hiperconto não precisa utilizar todos esses recursos ao mesmo tempo, assim como há filmes belíssimos sem efeitos especiais. (SPALDING, 2010, on-line, grifo do autor).

Com isso, podemos compreender o hiperconto como um gênero que compreende variadas tecnologias em sua forma, podendo haver diversos recursos tecnológicos ao mesmo tempo em um único texto ou podendo haver poucos recursos, desde que estes existam. Para o autor, o uso desses recursos enriquece o texto, pois proporcionam sensações nos leitores, entretanto o conteúdo temático deve ser o foco principal do autor e dos leitores do hiperconto, enquanto que os recursos midiáticos irão enriquecer a escrita, não devendo ser mais evidenciados do que o próprio texto.

De acordo com Dias (2012) os processos interativos nos hipertextos acrescentam nas produções de sentidos, havendo casos em que o leitor irá interagir com o texto através de links, potencializando assim a sua significação. Para a autora esse processo de interação, permitida pelos gêneros digitais, convida os leitores para uma melhor compreensão do texto e dá maior autonomia no processo de criação textual. Sendo assim, o hiperconto permite que o leitor interaja com o texto, fazendo com que ele se sinta parte do processo de produção.

Concluímos que o hiperconto é um gênero em ascensão, pois assim como os outros gêneros digitais, está cada vez mais fazendo parte do cotidiano da atual sociedade. Com isso, percebemos o hiperconto como um gênero escrito multissemiótico, que se assemelha ao conto tradicional por sua característica narrativa e se diferencia por sua natureza interativa na qual o leitor irá interagir com o texto usando dos recursos que esse texto oferece, como: imagens, links, áudios, etc. Assim, é importante que a escola volte seu olhar para os gêneros digitais, gêneros esses que exigirão de seus leitores e autores os multiletramentos.

\section{UMA INTERVENÇÃO PEDAGÓGICA ATRAVÉS DA RETEXTUALIZAÇÃO DA CANÇÃO PARA O HIPERCONTO.}


Pensando nessa nova visão de ensino de língua e de gêneros desenvolvemos uma proposta de retextualização que envolve prática multiletradas, mostrando que a língua não é estática e precisa se adequar à sociedade na qual vivemos. Essa proposta está destinada a estudantes do $2^{\circ}$ ano do Ensino Médio, com o intuito de aperfeiçoar e desenvolver as habilidades de leitura e produção, assim como de formar cidadãos críticos e competentes nas práticas comunicativas de sua língua.

A proposta está organizada em seis etapas distintas, que devem promover a aprendizagem gradativa dos gêneros orais e escritos, sendo que os momentos devem acontecer em aulas geminadas. Portanto estima-se a duração de 12 horas aula para a aplicação dessa proposta de intervenção em sala de aula.

\section{$1^{\text {a }}$ ETAPA: DURAÇÃO DE 1 H/AULA}

No primeiro momento será apresentada a turma a proposta de trabalho que será realizada com eles. Essa apresentação será feita através de um cronograma, mostrando um esquema das etapas que serão realizadas.

Em seguida, apresentaremos o gênero canção, questionando quem o conhece e quais suas características. Para isso é importante considerar o conhecimento prévio dos estudantes, para depois realizar a explanação da estrutura composicional de uma canção e do que é um gênero oral, fazendo a diferenciação entre gêneros orais e escritos. Em seguida reproduziremos o áudio da canção Riacho do Navio de autoria de Luiz Gonzaga. Vejamos a canção:

Quadro 1 - Canção Riacho do Navio

\begin{tabular}{|ll}
\hline $\begin{array}{l}\text { Riacho do Navio } \\
\text { Luiz Gonzaga }\end{array}$ & \\
Riacho do Navio & \\
Corre pro Pajeú & E nesse desafio \\
O rio Pajeú vai despejar & Saía lá do mar pro \\
No São Francisco & Riacho do Navio \\
O rio São Francisco & Eu ia direitinho pro \\
Vai bater no mei do mar & Riacho do Navio \\
O rio São Francisco & \\
Vai bater no mei do mar & Pra ver o meu brejinho \\
& Fazer umas caçada \\
& Ver as pegá de boi \\
\hline
\end{tabular}




\section{Riacho do Navio}

Corre pro Pajeú

O rio Pajeú vai despejar

No São Francisco

O rio São Francisco

Vai bater no mei do mar

O rio São Francisco

Vai bater no mei do mar

Ah! se eu fosse um peixe

Ao contrário do rio

Nadava contra as águas
Andar nas vaquejada
Dormir ao som do chocalho
E acordar com a passarada
Sem rádio e sem notícia
Das terra civilizada
Sem rádio e sem notícia
Das Terra civilizada
Riacho do navio
Riacho do navio
Riacho do navio
Tando lá não sinto frio

Fonte: Riacho do Navio. Luiz Gonzaga. https://www.letras.mus.br/luiz-gonzaga/47101/

Após a escuta da canção, debateremos o texto ouvido com os estudantes, estes, por sua vez, devem expor suas opiniões e compreensões quanto à estrutura, a temática e o propósito comunicativo.

\section{$2^{\mathrm{a}}$ ETAPA: 2 HORAS/AULA}

Na segunda etapa abordaremos o gênero hiperconto, retomando o que foi estudado na etapa anterior. Logo depois questionaremos acerca do uso das tecnologias e apresentaremos o gênero hiperconto, por ser um gênero novo e que provavelmente os estudantes ainda não o conheçam. Essa apresentação deve partir de o que é um conto até chegar ao hiperconto.

Para isso, é importante que fique bem claro que o hiperconto não é um conto apenas digitado, mas um gênero com uma estrutura composicional própria e que é essencial que, esse como qualquer outro gênero digital, seja produzido e veiculado em plataforma digital. Assim, o hiperconto é uma narrativa curta que deve englobar recursos tecnológicos para intensificar o conteúdo trazido na narração.

Após esta exposição conduziremos os estudantes para a sala de informática e, em seguida explicaremos os passos eles a serem seguidos.

No primeiro passo eles devem abrir o navegador da internet e fazer a pesquisa pelo site <http://www.hiperconto.com.br/>, depois, farão a leitura do hiperconto Um estudo em vermelho de Marcelo Spalding. Nesse momento os estudantes perceberão na prática como este gênero é interativo e é preciso do domínio básico das ferramentas tecnológicas para realizar a sua leitura. 
Depois, o professor deve mediar a análise no texto que será feita coletivamente, assim, ele poderá nortear as discussões chamando a atenção a alguns pontos, como: o espaço, os personagens, o tempo, o tema abordado, qual o seu clímax e qual o desfecho. Posteriormente, será organizada uma roda de conversa, na qual os estudantes serão convidados a expor o que eles acharam do gênero lido, se este é atrativo, o que eles gostaram mais, etc.

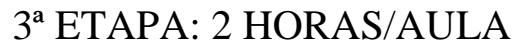

Tendo então conhecido os dois gêneros que serão usados no processo de retextualização, apresentaremos aos estudantes o processo de retextualização. Nesse momento, faremos uma exposição oral através de power Point, explicando que a retextualização é a passagem do texto em uma ordem para o texto em outra ordem, como esta acontece e quais passos devem ser seguidos para que haja sucesso nesse processo.

Depois comentaremos que para realizar esse processo é necessário que sejam analisados os elementos linguísticos presentes no texto e também todos os critérios de textualidade para que consideremos o texto e seus sentidos. É importante ressaltar que nesse momento é necessário, apresentarmos os aspectos envolvidos na retextualização segundo Marcuschi (2010), a eliminação, a completude, a regularização, o acréscimo, a substituição, a reordenação, o tratamento da sequência dos turnos, a inferência, a inversão e a generalização.

\section{$4^{\text {a }}$ ETAPA: 2 HORAS/AULA}

Está etapa será o momento em que os estudantes conhecerão o texto base, canção, que eles irão usar para produzir a sua retextualização. Para isso, apresentaremos, por meio de aparelho de som, a canção A morte do meu avô de Luiz Gonzaga:

Quadro 2- Canção A morte do meu avô

\begin{tabular}{|c|c|}
\hline \multicolumn{2}{|l|}{$\begin{array}{l}\text { A Morte do Meu Avô } \\
\text { Luiz Gonzaga }\end{array}$} \\
\hline Eu era pirritotinho & $\mathrm{Na}$ reza forte encontrei \\
\hline Quando mamãe decretou & A minha religião \\
\hline Você é quem vai vingar & A minha religião \\
\hline
\end{tabular}

A Morte do Meu Avô

Luiz Gonzaga

Eu era pirritotinho

A minha religião

Você é quem vai vingar 

A morte do seu avô (bis)
Ganhei punhal enfeitado
Daquela que me criou
Crescí pensando em vingar
A morte do meu avô
A morte do meu avô (bis)
Vida triste, triste vida
Vida triste, meu viver
Eu já tinha inimigo
Muito antes de nascer \} bis
Cartilha era o meu rifle
Caneta o meu punhá
Eu na caatinga entrei
Aonde fui estudar (bis)
A professora era o ódio
Cangaço educação
A minha religião
Eu queria ser alegre
Eu queria namorar
Eu queria uma viola
Eu queria o luar
Mas eu fui o escolhido
Tinha mesmo que matar
Se o ódio e a vingança
Tem força de satanás
Mais força tem o amor
Fazendo o que ninguém faz (bis)
Mostrou-me a providência
Os olhos de Guiomar
Eu nunca mais atirei
Guardei inté meu punha
Guardei inté meu punha (bis)

Fonte: A Morte do Meu Avô. Luiz Gonzaga. https://www.letras.mus.br/luiz-gonzaga/1560724/

Em seguida, será feito uma atividade de interpretação textual para nortear a compreensão dos estudantes. Logo após essa atividade, organizaremos uma roda de discussão sobre o texto.

Destacamos que um texto só pode ser retextualizado diante da compreensão do texto base, por isso essa fase do trabalho de conhecimento e compreensão do texto base merece uma maior atenção, pois ele está diretamente ligado ao nosso objetivo final.

\section{$5^{\circ}$ ETAPA: 2 HORAS/AULA}

A quinta etapa é a fase da retextualização propriamente dita, assim é importante que aqui tenhamos uma linguagem clara e concisa para que os estudantes entendam o que deles se espera e quais passos seguir para chegar ao seu objetivo. Para isso, explicaremos a proposta de retextualização, na qual eles produzirão um texto do gênero hiperconto a partir do texto base A morte do meu avô, que pertence ao gênero canção.

É pertinente reavivar a memória dos estudantes no momento da produção, no que diz respeito à estrutura composicional do gênero hiperconto, além de considerar os recursos 
semióticos digitais que podem ser dentre esses: áudios, imagens interativas ou não, links, entre outros recursos.

Os estudantes serão conduzidos para a sala de informática, na qual eles serão divididos em duplas para cada computador. Vale ressaltar que esse momento será mais eficiente se houver uma parceria entre o professor de língua portuguesa e o professor de informática, uma vez que este pode auxiliar os estudantes com o manuseio e uso dos recursos tecnológicos digitais.

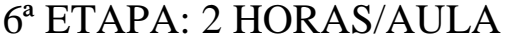

Por fim, os alunos publicarão suas produções e as apresentarão aos demais colegas. Para isso, essa aula deve acontecer no laboratório de informática, onde os estudantes, em duplas, serão orientados a publicar seus hipercontos. Essa publicação será feita por meio de um blog específico para esta atividade, tendo por administrador o professor responsável.

A dupla responsável pela produção deve apresentar seu texto, quais suas estratégias para fazer a retextualização, quais recursos utilizaram e por que os utilizaram. Essa apresentação ocorrerá por meio de projetor multimídia (Data show), pois por ser um gênero digital deve veicular em meios digitais e eletrônicos.

Enfim, esperamos que essa experiência pedagógica propicie momentos de interação e de troca de conhecimentos, para que assim, os estudantes desenvolvam as habilidades leitoras e produtoras de forma significativa, assim como se tornem estudantes multiletrados competentes no uso das diversas linguagens e estruturas digitais.

\section{CONSIDERAÇÕES FINAIS}

Esta pesquisa se propôs a compreender o processo de retextualização do gênero canção para o gênero hiperconto, por meio dos multiletramentos, como prática pedagógica motivadora e significativa para os alunos do século XXI.

No que se refere ao processo de retextualização, defendido por Marcuschi (2010), esse foi um importante norteador nesta pesquisa, uma vez que, é por meio deste que podemos trabalhar com os gêneros textuais numa nova perspectiva. Exemplo disso, podemos citar 
pessoas que produzem gêneros orais com naturalidade, mas que no momento de produções escritas apresentam dificuldades. Nesse sentido, a retextualização contribui para o aperfeiçoamento da produção escrita de diferentes gêneros textuais, através de sua estrutura composicional e funcionalidade comunicativa na língua.

Percebemos a importância da prática dos multiletramentos, para trabalhar a multiplicidade de linguagens, culturas e recursos midiáticos, e como estes auxiliam no ensino de língua, confirmando assim o que Rojo (2012) diz com relação à formação de sujeitos reflexivos, atuantes e autônomos na sociedade em que vivem.

A proposta de intervenção aqui apresentada tem o intuito de colaborar com a prática docente dos professores de Língua Portuguesa, através de um processo de retextualização da canção para o hiperconto. Essa se justifica por ter gêneros textuais que fazem parte da realidade dos estudantes em suas situações de comunicação diária e também por serem textos atraentes e consequentemente motivadores.

\section{REFERÊNCIAS BIBLIOGRÁFICAS}

COSTA, Nelson Barros da. As letras e a letra: o gênero canção na mídia literária. In: DIONISIO, Angela Paiva; MACHADO, Anna Rachel; BEZERRA, Maria Auxiliadora (Orgs). Gêneros textuais \& ensino. São Paulo: Parábola Editorial, 2010.

DIAS, Anair Valênia Martins. Hipercontos multissemióticos: para a promoção dos multiletramentos. In: ROJO, Roxane Helena Rodrigues. Multiletramentos na escola. São Paulo: Parábola Editorial, 2012.

MARCUSCHI, Luiz Antônio. Da fala para a escrita: atividades de retextualização. 10. ed. São Paulo: Cortez, 2010.

Gêneros textuais: definição e contextos. In: DIONISIO, Angela Paiva; MACHADO, Anna Rachel; BEZERRA, Maria Auxiliadora (Orgs). Gêneros textuais \& ensino. São Paulo: Parábola Editorial, 2010.

ROJO, Roxane Helena Rodrigues. Multiletramentos na escola. São Paulo: Parábola Editorial, 2012. 
SPALDING, Marcelo. O hiperconto e a literatura digital. Digestivo Cultural. Porto Alegre, abr. 2010.

Disponível

em:

$<$ http://www.digestivocultural.com/colunistas/coluna.asp?codigo $=3034 \&$ titulo $=0$ _hiperconto _e_a_literatura_digital >. Acesso em: 27 jul.2017.

TATIT, Luiz. Elementos para a análise da canção popular. Cadernos de Semiótica Aplicada, São Paulo, v. 1, n. 2, dez. 2003. Disponível em $\langle$ http://seer.fclar.unesp.br/casa/article/view/623/538>. Acesso em: 27 jul.2017. 